\title{
Potential Use of Calcined Silt of Dam as a Pozzolan in Blended Portland Cement
}

\author{
Bahia Rabehi ${ }^{1), *}$, Youcef Ghernouti ${ }^{1)}$, and Miloud Driss ${ }^{2)}$
}

(Received July 18, 2013, Accepted February 26, 2014)

\begin{abstract}
This paper presents results of an experimental study which investigates the effect of industrial pozzolan made from calcined silt of dam at $750{ }^{\circ} \mathrm{C}$ for $5 \mathrm{~h}$, on mechanical properties and durability of ordinary mortar, compared to the silica fume. Mortar specimens prepared with 5, 10 and $15 \%$ of calcined silt to substitute cement were evaluated for their compressive and flexural strength, sulfate, acid and penetration of chloride ions resistance. The results were compared with ordinary mortar (without addition) and mortar containing $10 \%$ of silica fume. The results obtained showed that the calcined silt of dam has a high potential to be used as a pozzolanic material, it improves the strength and the durability of mortar and compete the silica fume.
\end{abstract}

Keywords: mortar, addition, durability, strength, silt of dam, pozzolanic activity.

\section{Introduction}

A large number of studies (Mehta 1981; Ramezanianpour 1987; Massazza 1993; Kouloumbi et al. 1995; RodriguezCamacho 1998; Tagnit-Hamou et al. 2003) have shown that natural pozzolana have been widely used as a substitute for Portland cement in many applications because of their advantageous properties which include cost reduction, reduction in heat evolution, decreased permeability and increased chemical resistance. However, they are often associated with shortcomings such as the need to moistcuring for longer time and a reduction of strength at early ages and up to 28 days.

The use of calcined clay as a pozzolanic material for mortar and concrete has received considerable attention in recent years (Ambroise et al. 1992; Sabir et al. 2001; Al Rawas et al. 2001; Shvarzman et al. 2002). This interest is part of the widely spread attention directed towards the utilization of wastes and industrial byproducts in order to minimize Portland cement consumption, whose the manufacture whether harmful to the environment (Nkinamubanzi and Aitcin 2000).

Another reason is that mortar and concrete, which contain pozzolanic materials exhibit considerable enhancement in durability properties (Kostuch et al. 1993; Bager et al. 2001).

\footnotetext{
${ }^{1)}$ Research Unit: Materials, Processes and Environment, University M'Hamed Bougara of Boumerdes, Boumerdes, Algeria.

*Corresponding Author; E-mail: rabehi@umbb.dz

${ }^{2)}$ Laboratory of Sciences and Water Technical, University of Mascara, Mascara, Algeria.
}

Copyright ( $\odot$ The Author(s) 2014. This article is published with open access at Springerlink.com
It has been reported that the concrete incorporating $10 \%$ of metakaolin (MK) had a higher compressive strength than the control Portland cement concrete at all ages up to 180 days (Sabir et al. 1996; Zhang and Malhotra 1995).

Siltation of dams can have the most dramatic erosion consequences; it takes a sufficient extent in Algeria. The spill is an effective way to fight, nevertheless, it creates another problem which is; "where we put the evacuated silt?", without causing an ecologic problem!. This problem is always aroused the interest of researchers in the field of water resources. The purpose of this study is focused to this issue in recovery view, which makes it possible to valorize this silt by use in the field of civil engineering.

\section{Experimental Investigation}

\subsection{Materials}

The mortar mixtures investigated in this study were prepared with Portland cement (PC) CEMI.42.5R. Natural sand having a fineness modulus of 1.5 with $2 \mathrm{~mm}$ maximum aggregate size was used. The specific gravity and water absorption values were obtained as 2.62 and $0.8 \%$ respectively.

Two additions were used in this work:

- Calcined silt (CS): silt used in this study was taken from stockpiles of dredged material (Dam of CHOURFA in the North-West Algeria). It was calcined at a temperature of $750{ }^{\circ} \mathrm{C}$ for $5 \mathrm{~h}$. The calcined silt (CS) are crushed and then further pulverized in a ball mill until the particles could pass through an $80 \mu \mathrm{m}$.

- Silica fume (SF) named MEDAPLAST HP from the Granitex Company (Algeria), containing $94 \% \mathrm{SiO}_{2}$, it is a pozzolanic addition with gray color, used in the formulation of high performance concrete (HPC). 
Chemical composition and specific gravity of the PC, CS and SF are given in Table 1.

\subsubsection{Preparation of Metakaolin}

We prepared metakaolins in the following steps (Fig. 1):

After drying in an oven at $105^{\circ} \mathrm{C}$, the clay (silt of dam) was crushed and sieved. The calcination temperature is about $750{ }^{\circ} \mathrm{C}$ for $5 \mathrm{~h}$ (Aquino et al. 2001; Guneyisi et al. 2008; Safi et al. 2011, 2012), Generally, an optimum for kaolin clay calcinations recognized in literature is between 600 and $900{ }^{\circ} \mathrm{C}$ (Ambroise et al. 1986; Sayanam et al. 1989). The product obtained (calcined silt) was kept away from air and humidity. Particles passing $80 \mu \mathrm{m}$ are recovered for later use in the preparation of mortars.

Figure 2, shows the granulometric distribution of materials established by a Laser-granulometer of Malvern instrument-MASTERSIZER 2000.

The size analysis of the all additions using a Laser grain size indicates that the fraction of grains lower than $80 \mu \mathrm{m}$ is $80 \%$.

\subsection{Mixture Proportions}

The different mortars were elaborated by using normal mortars, according to the norm NFP 15-403 (NF P 1996), of comparison. The water-binder ratio used is to keep constant $(\mathrm{W} / \mathrm{B}=0.5)$ and the sand-cement ratio is also to keep constant $(\mathrm{S} / \mathrm{C}=3)$. The normal mortar describes previously is produced using a mixer HOBART, in a tank of five liters spreading with the characteristics of standard NFP 15-411 (NF P 1996). The calcined silt was introduced by substitution of a variable percentage of cement such as: 5, 10 and $15 \%$ and that, to better see their influence on the mechanical and physical properties as well as behavior of these mortars with the chemical attacks. The different compositions of mortars studied and their notations are presented in Table 2.

\subsection{Casting, Curing and Testing Specimens}

All the mortar were mixed and prepared using a mortar mixer with a vertical axis and a capacity of 51 . The Curing and Testing of different specimens used in this study are summarized in the following organization chart (Fig. 3). From each mortar mixture, five (5) prismatic molds of $(4 \times 4 \times 16) \mathrm{cm}^{3}$ and six (6) cubic samples of $(10 \times 10 \times 10) \mathrm{cm}^{3}$ are prepared, in totality seventy five (75) samples of $(4 \times 4 \times 16) \mathrm{cm}^{3}$ and thirty (30) samples of $(10 \times 10 \times 10) \mathrm{cm}^{3}$ are elaborated. One part of the samples $(4 \times 4 \times 16) \mathrm{cm}^{3}$ were conserved in the water for the flexural and compressive strength tests at 7, 28 and 60 days, other part of this samples were conserved 28 days in water they were then conserved in two medium $\mathrm{H}_{2} \mathrm{SO}_{4}$ and $\mathrm{Na}_{2} \mathrm{SO}_{4}$ for the durability tests. The samples $(10 \times 10 \times 10) \mathrm{cm}^{3}$ were conserved 28 days in water saturated with lime, after that they were conserved in $\mathrm{NaCl}$ medium for the determination of penetration chloride ions at 28 and 60 days.

\section{Results and Discussions}

\subsection{Pozzolanic Reactivity of Additions Used}

The study of the pozzolanic reactivity of the additions used was inspired by the test Chapelle (Chinje and Billong 2004; Bénoît 1969), which is to determine the difference between the initial and final concentration of lime solution and allowing determining the rate of $\mathrm{CaO}$ fixed by the additions. The results of the pozzolanic reactivity of all additions are shown in Table 3 and Fig. 4. The pozzolanic reactivity is indicated by the amount of $\mathrm{CaO}$ fixed by calcined clays and additions. All results of the samples show a decrease of the concentration of $\mathrm{CaO}$ in the lime solution. This decrease is more advanced in the case of silica fume is of the order of $95 \%$. The silica fume is a material known by its reactivity with pozzolanic its

Table 1 Chemical composition (\% in mass) and specific gravity of starting materials.

\begin{tabular}{c|c|c|c}
\hline & Portland cement (PC) & Silica fume (SF) & Calcined silt (CS) \\
\hline \hline $\mathrm{SiO}_{2}(\%)$ & 21.1 & 94.30 & 51.36 \\
\hline $\mathrm{Al}_{2} \mathrm{O}_{3}(\%)$ & 4.2 & 0.69 & 12.78 \\
\hline $\mathrm{Fe}_{2} \mathrm{O}_{3}(\%)$ & 5.32 & 0.14 & 5.18 \\
\hline $\mathrm{CaO}(\%)$ & 61.8 & 1.17 & 17.08 \\
\hline $\mathrm{MgO}(\%)$ & 2.3 & 0.29 & 2.29 \\
\hline $\mathrm{SO}_{3}(\%)$ & 2.0 & 0.00 & 0.00 \\
\hline $\mathrm{Na}_{2} \mathrm{O}+\mathrm{K}_{2} \mathrm{O}(\%)$ & 0.6 & 1.67 & 2.42 \\
\hline $\mathrm{LOI}^{(\%)}$ & 2.28 & - & 7.06 \\
\hline $\left.\mathrm{SiO}_{2}+\mathrm{Al}_{2} \mathrm{O}_{3}+\mathrm{Fe} \mathrm{O}_{3}\right](\%)$ & 30.62 & 95.13 & 69.32 \\
\hline$\sum(\%)$ & 99.64 & 98.26 & 98.17 \\
\hline $\mathrm{Specific} \mathrm{gravity}^{2}$ & 3.1 & 2.71 & 2.38 \\
\hline
\end{tabular}




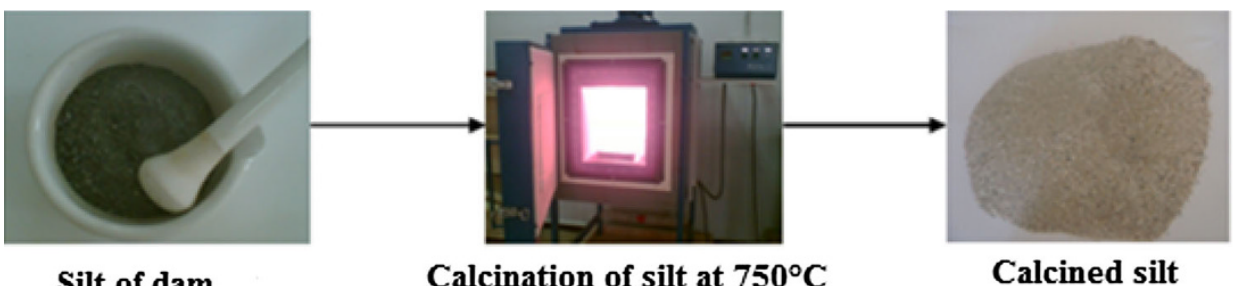

Silt of dam

Calcination of silt at $750^{\circ} \mathrm{C}$

Calcined silt

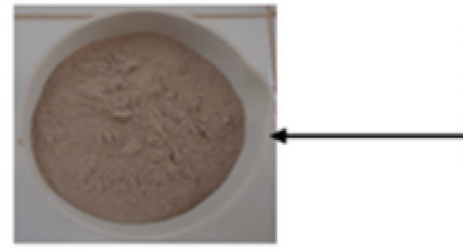

Metakaolin

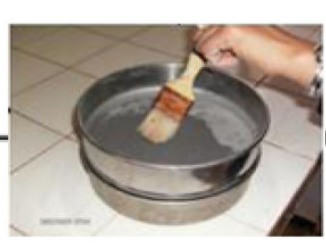

Seiving at $0.080 \mathrm{~mm}$

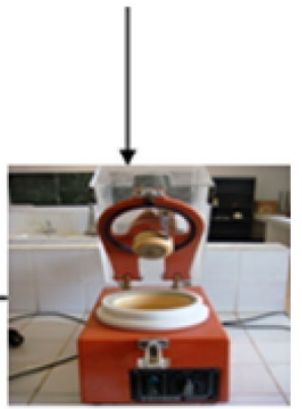

Crushing

Fig. 1 Preparation of metakaolin (calcined silt).

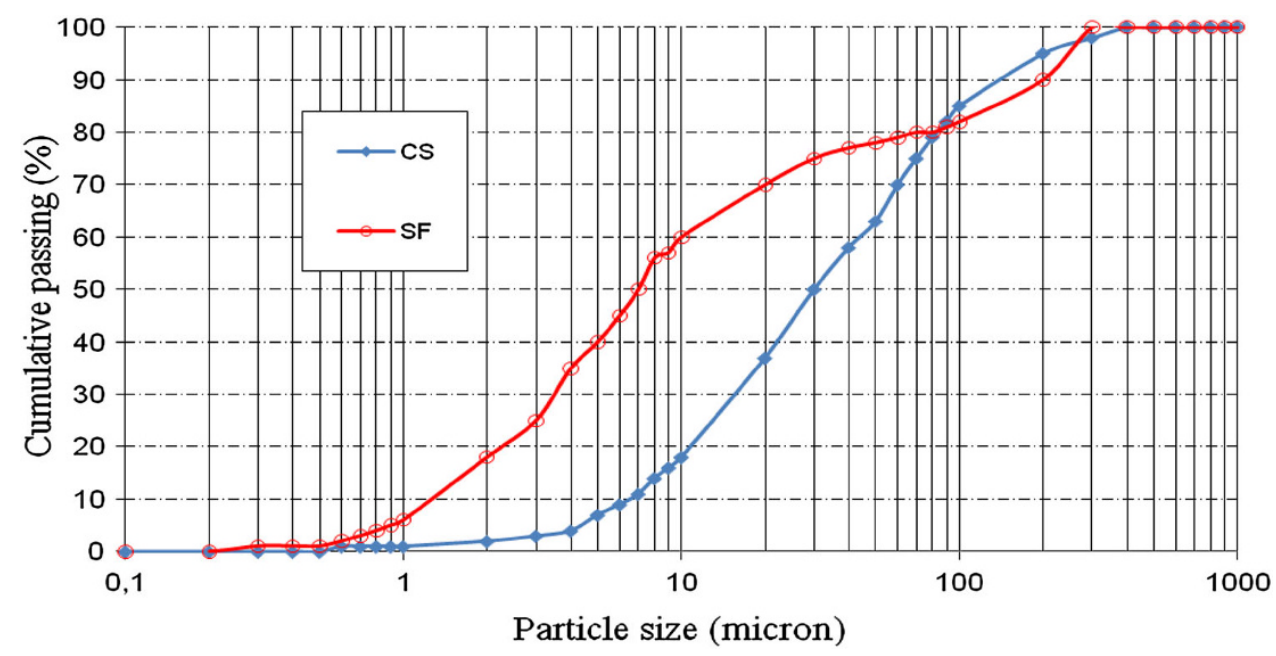

Fig. 2 Particle size distribution of additions used.

Table 2 Mix proportions of the mortars $\left(\mathrm{kg} / \mathrm{m}^{3}\right)$.

\begin{tabular}{|c|c|c|c|c|c|c|}
\hline Notation & Description & $\begin{array}{l}\text { Portland cement } \\
\text { (PC) }\end{array}$ & Water (W) & Sand (S) & Calcined silt (CS) & Silica fume (SF) \\
\hline $\mathrm{OM}$ & Ordinary mortar & 586 & \multirow[t]{5}{*}{293} & \multirow[t]{5}{*}{1,758} & 0 & 0 \\
\hline MCS1 & $\begin{array}{c}\text { Mortar with } 5 \% \\
\text { calcined silt }\end{array}$ & 556.7 & & & 29.3 & 0 \\
\hline MCS2 & $\begin{array}{c}\text { Mortar with } 10 \% \\
\text { calcined silt }\end{array}$ & 527.4 & & & 58.6 & 0 \\
\hline MCS3 & $\begin{array}{l}\text { Mortar with } 15 \% \\
\text { calcined silt }\end{array}$ & 498.1 & & & 87.9 & 0 \\
\hline MSF & $\begin{array}{c}\text { Mortar with } 10 \% \\
\text { silica fume }\end{array}$ & 527.4 & & & 0 & 58.6 \\
\hline
\end{tabular}

contains more than $98 \%$ of amorphous silica that will react with the portlandite $\mathrm{Ca}(\mathrm{OH})_{2}$ released during the hydration of cement.
Metakaolin obtained from calcined silt (CS), has a pozzolanic reactivity relatively high $(75 \%)$ which has the value closest to that of silica fume. 


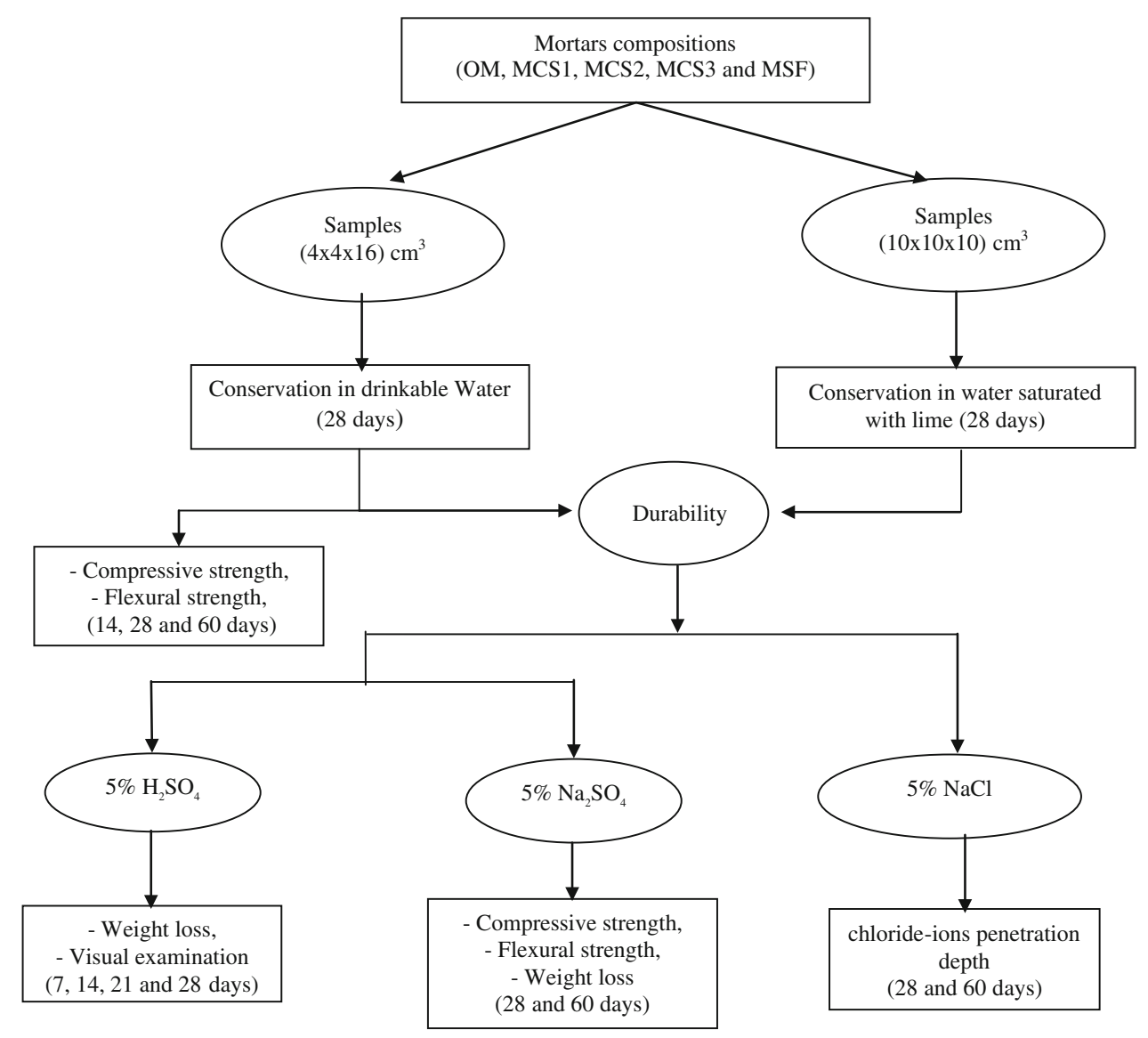

Fig. 3 Testing program.

Table 3 Amount of lime fixed by the additions.

\begin{tabular}{c|c|c|c}
\hline \multirow{2}{*}{ additions } & Concentration of $\mathrm{CaO}(\mathrm{g} / \mathrm{L})$ & \multicolumn{2}{|c}{ Fixed amount of $\mathrm{CaO}$} \\
\cline { 3 - 4 } & & Concentration $(\mathrm{g} / \mathrm{L})$ & Percentage $(\%)$ \\
\hline \hline $\mathrm{SF}$ & 0.06 & 1.12 & 95 \\
\hline $\mathrm{CS}$ & 0.3 & 0.88 & 74.5 \\
\hline
\end{tabular}

The calcinations of silt at $750{ }^{\circ} \mathrm{C}$ allows the departure of the water content (the dehydroxylation) and the formation of metakaolin (Samet et al. 2007; Michel 1989) with an amorphous structure which makes it more reactive than the starting clay. It is an acid-base reaction, which explains the strong decrease in $\mathrm{CaO}$ concentration of the solution. The heat treatment causes the transition of the crystalline phase ordered (kaolinite) to a disordered phase (metakaolinite) by a collapse of the crystal lattice. Metakaolinite is considered a good synthetic pozzolans, through its particular reaction with lime in the presence of water to form compounds of the silicate and aluminate calcium hydrates (Wild and Khatib 1997; Frias et al. 2000; Poon et al. 2001).

\subsection{Mechanical Strength}

Compressive and flexural strength are determined according to standard NF-P-15-401 (NFP 1996) and NF-P15-400 (NFP 1996), respectively. The results of the evolution of mechanical strength test specimens of mortars, kept in water for 14, 28 and 60 days are shown in Figs. 5 and 6.

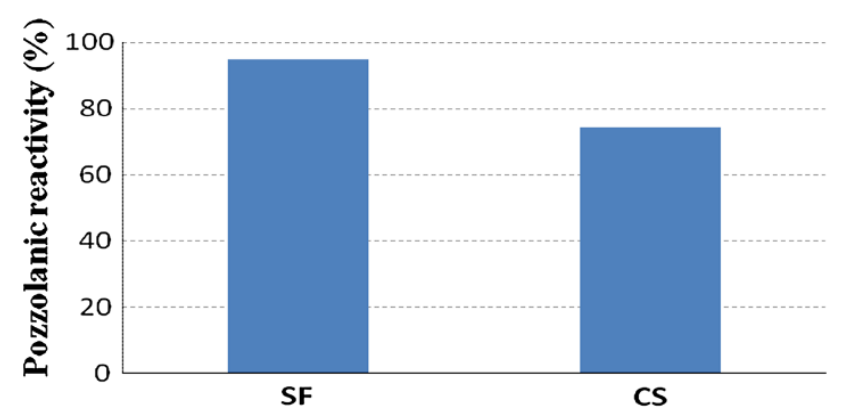

Fig. 4 Pozzolanic reactivity of the additions.

The compressive strength gain at 28 days for different compositions with additions of calcined silt (CS) compared to the reference mortar is shown in Fig. 7.

For all the mortar compositions, we noted a continuous increase in the compressive and flexural strength according to the age 14, 28, and 60 days. This phenomenon is due to hydration of cement which causing changes in the compactness over time, because the hydration of cement constituents 


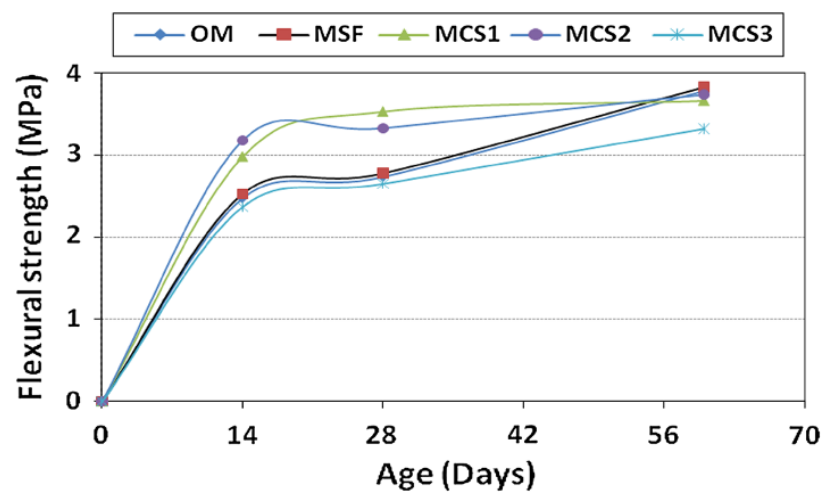

Fig. 5 Flexural strength of mortars at different ages.

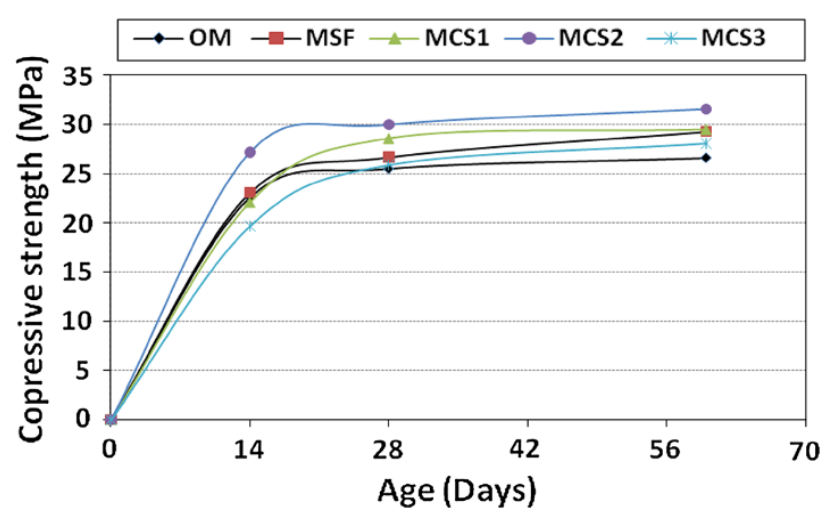

Fig. 6 Compressive strength of mortars at different ages.

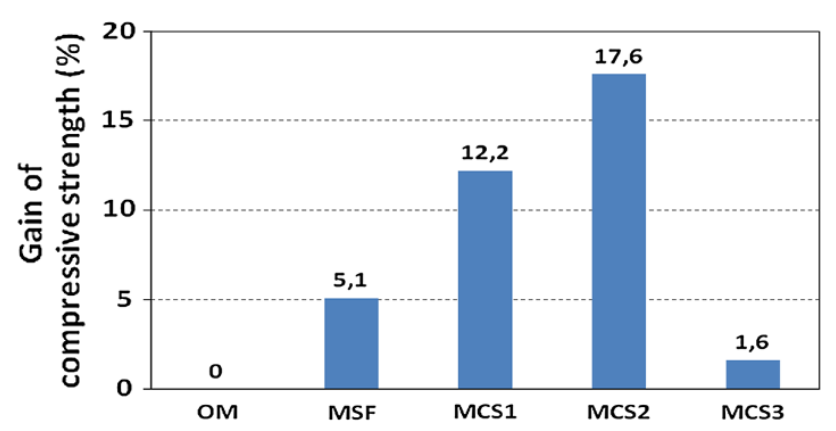

Fig. 7 Compressive strength gain of at 28 days compared to the ordinary mortar.

$\mathrm{C}_{3} \mathrm{~S}$ and $\mathrm{C}_{2} \mathrm{~S}$ lead to the formation of $\mathrm{CSH}$ which increased the strength (Chinje and Billong 2004; Baronio and Binda 1997). An improvement for about $18 \%$ of the compressive strength at 28 days is identified relative to the reference mortar for the addition of $10 \%$ of calcined silt, despite the partial replacement of a cement part, responsible of the much strength of the mortar as it has been demonstrated in several studies (Janotka 1999; Said-Mansour et al. 2005; Rossignolo and Agnesini 2004). The strength augmentation is mainly due to the pozzolanic property of the silt of dam that acquires a certain pozzolanic activity after the calcinations at a temperature of $750{ }^{\circ} \mathrm{C}$ where some clay minerals such as Kaolin, which processed that lead to disordered phase (Metakaolin). This phase has an amorphous structure or partially amorphous in the presence of $\mathrm{Ca}(\mathrm{OH})_{2}$ and water give birth to new formations $(\mathrm{CSH}$, $\mathrm{CAH}$ ), with similar properties to those formed based on mineral cement. At 28 days, all mortars with additions of calcined silt or silica fume, show evidence of pozzolanic activity (Table 4) more than $100 \%$, this confirms the strong pozzolanicity of these additions while the ASTM C 618 (ASTM C 618 2000) standard requires a minimum pozzolanic activity index of $75 \%$ at 28 days with Portland cement artificial (Butler 1982).

\subsection{Durability of Mortars 3.3.1 Sulfuric Acid Effect}

To characterize the chemical resistance in acidic medium, mortars were cast into prismatic molds $(4 \times 4 \times 16) \mathrm{cm}^{3}$. $24 \mathrm{~h}$ later, samples were removed from the molds and kept in cleansed water. After 28 days of treatment, the samples are immersed in a solution of $5 \%$ of a strong acid sulfuric $\left(\mathrm{H}_{2} \mathrm{SO}_{4}\right)$ : the change in weight of specimens was examined after $7,14,21$ and 28 days. The chemical solution is renewed every 7 days. In the examination day, affected parts of mortar are cleanse with water, and the samples were dried for half an hour (ASTM C 267-96 2001), and finally chemical resistant were assessed by measuring the mass loss of the specimen.

Table 5 represent the evolution of the weight loss depending on time of various mortars conserved in the strong acid solution $\left(\mathrm{H}_{2} \mathrm{SO}_{4}\right)$.

Figure 8 shows the change in aspect of the various mortars (OM, MSF, MCS1, MCS2 and MCS3) after 28 days of immersion in a solution of $5 \%$ of strong acid $\left(\mathrm{H}_{2} \mathrm{SO}_{4}\right)$.

The weight loss of mortars increases with the immersion period. Also note that the weight loss of the mortar with additions is significantly lower than the ordinary mortar, and it reduces especially with 5 and $10 \%$ of calcined silt and silica fume. Silica fume mortar showed $42.76 \%$ weight loss compared to 29.21 and $38.47 \%$ for mortar with 5 and $10 \%$ of calcined silt, respectively. This is can certainly be related to the presence of high lime content in calcined silt $(17 \%)$ compared to the low content lime $(1 \%)$ in silica fume, the

Table 4 Strength activity index during 28 days.

\begin{tabular}{c|c|c}
\hline Mortars & Compressive strength at 28 days (MPa) & Strength activity index (\%) \\
\hline OM & 25.5 & 100 \\
\hline MSF & 26.7 & 104.7 \\
\hline MCS1 & 28.6 & 112.15 \\
\hline MCS2 & 30 & 117.64 \\
\hline MCS3 & 25.9 & 101.56 \\
\hline
\end{tabular}


Table 5 Evolution of the weight loss of mortars conserved in $\mathrm{H}_{2} \mathrm{SO}_{4}$.

\begin{tabular}{c|c|c|c|c}
\hline \multirow{2}{*}{ Mortars } & \multicolumn{4}{|c}{ Weight loss (\%) } \\
\cline { 2 - 5 } & 7 days & 14 days & 21 days & 28 days \\
\hline \hline OM & 27.48 & 37.50 & 56.22 & 42.76 \\
\hline MSF & 13.27 & 14.03 & 36.83 & 29.21 \\
\hline MCS1 & 3.61 & 5.44 & 27.63 & 38.47 \\
\hline MCS2 & 7.35 & 10.45 & 23.38 & 40.83 \\
\hline
\end{tabular}

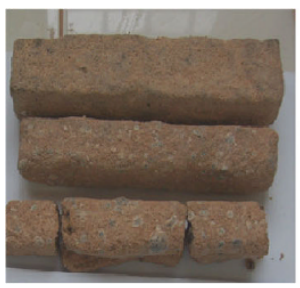

$O M$

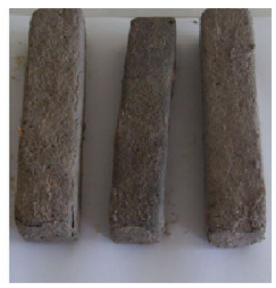

MSF

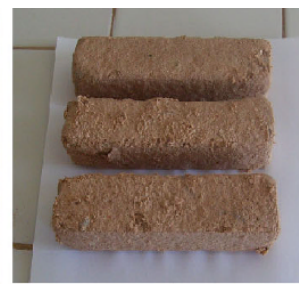

MCS1

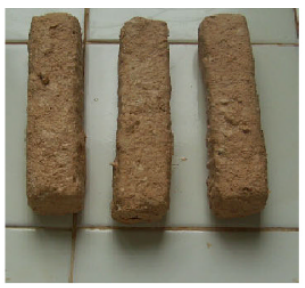

$\operatorname{MCS} 2$

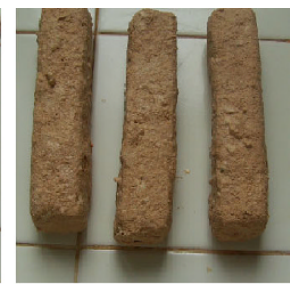

$\operatorname{MCS3}$

Fig. 8 State of specimens after immersion for 28 days in $5 \%$ of $\mathrm{H}_{2} \mathrm{SO}_{4}$.

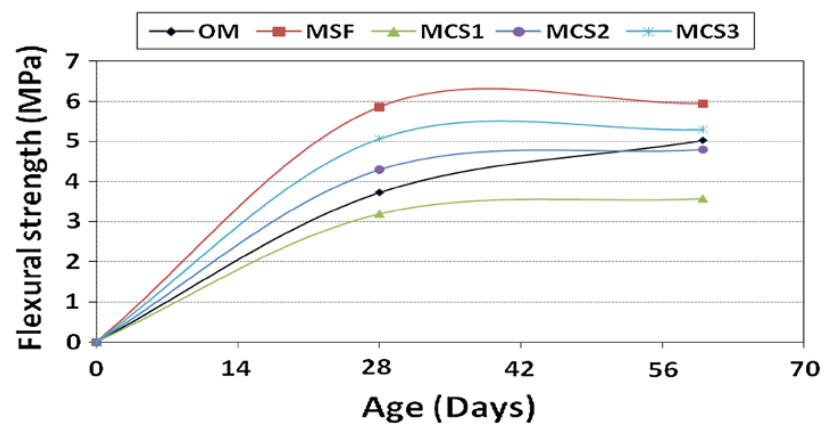

Fig. 9 Flexural strength of mortars at different ages kept in $\mathrm{Na}_{2} \mathrm{SO}_{4}$

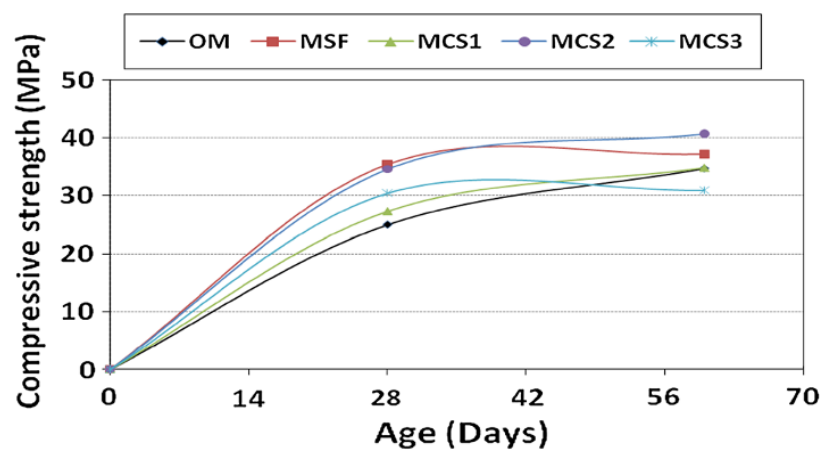

Fig. 10 Compressive strength of mortars at different ages kept in $\mathrm{Na}_{2} \mathrm{SO}_{4}$.

lime contribute to conserve the basic $\mathrm{PH}$ of specimens witch improve their durability in acid medium, consequently the weight loss is limited.

Sulfuric acid $\left(\mathrm{H}_{2} \mathrm{SO}_{4}\right)$ is an inorganic acid. These are more harmful to concretes and mortars than the organic acids. Inorganic acids come into reaction with $\mathrm{Ca}(\mathrm{OH})_{2}$ contained in the hardened cement paste formed compounds readily soluble in water.
It is useful to note that after 7 days of conserving in the solution of sulfuric acid, we have recorded a loss in mass.

This loss is due to deposit gypsum, which is formed following to the reaction between the portlandite $\left[\mathrm{Ca}(\mathrm{OH})_{2}\right]$ and sulfuric acid by chemical reaction:

$$
\mathrm{Ca}(\mathrm{OH})_{2}+\mathrm{H}_{2} \mathrm{SO}_{4} \rightarrow \mathrm{CaSO}_{4}+2 \mathrm{H}_{2} \mathrm{O} \text {. }
$$

The gypsum formed is then washed, which gives us a whitish solution, at the age of 14 and 28 days, for all types of mortars the weight loss increases but with different speeds. It is also noted that the mass loss is less important for mortars with additions to the reference mortar; which confirms the good behavior of these mortars in sulfuric attacks (Zivika and Bajz 2002; Ghrici et al. 2007).

\subsubsection{Sulfatic Solution Effect}

To assess the durability of mortars in the sulfates attacks, we have determined the compressive strength according to the duration of exposure to sulfates.

To characterize the chemical resistance in sulfatic solution, mortars were cast into prismatic molds $(4 \times 4 \times 16) \mathrm{cm}^{3} .24 \mathrm{~h}$ later, samples were removed from the molds and kept in clean water. After 28 days of treatment, the samples are immersed in a solution of $5 \%$ $\mathrm{Na}_{2} \mathrm{SO}_{4}$. The change in weight of specimens was examined after 7, 14, 21 and 28 days. The chemical solution is renewed every 7 days. In the examination day, affected parts of mortar are cleansed with water, and the samples were dried for half an hour.

Figures 9 and 10, presents the variation of flexural and compressive strength of the different types of mortar based on the duration of immersion in sulfate solution, after 28 and 60 days. Table 6 shows the gain or loss in compressive strength compared to the reference mortar for 60 days of immersion in solution of $\mathrm{Na}_{2} \mathrm{SO}_{4}$. 
Table 6 Gain or loss of compressive strength.

\begin{tabular}{c|c}
\hline Mortars & $\begin{array}{c}\text { Gain or loss of compressive strength compared } \\
\text { to OM in 60 days in (\%) }\end{array}$ \\
\hline \hline OM & 0.0 \\
\hline MSF & +7.2 \\
\hline MCS1 & +0.2 \\
\hline MCS2 & +17.3 \\
\hline MCS3 & -10.9 \\
\hline
\end{tabular}

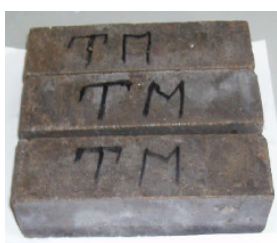

$\mathrm{OM}$

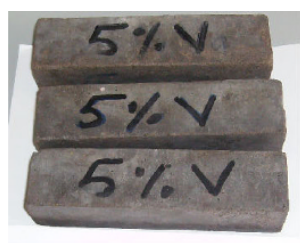

MCS1

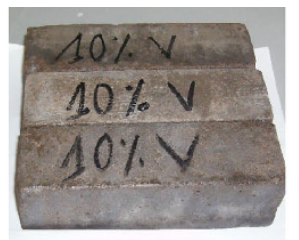

MCS2

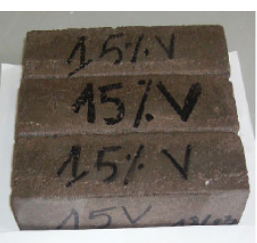

MCS3

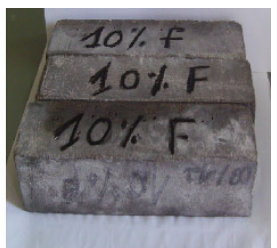

MSF

Fig. 11 State of the samples after 60 days of immersion in $\mathrm{Na}_{2} \mathrm{SO}_{4}$.

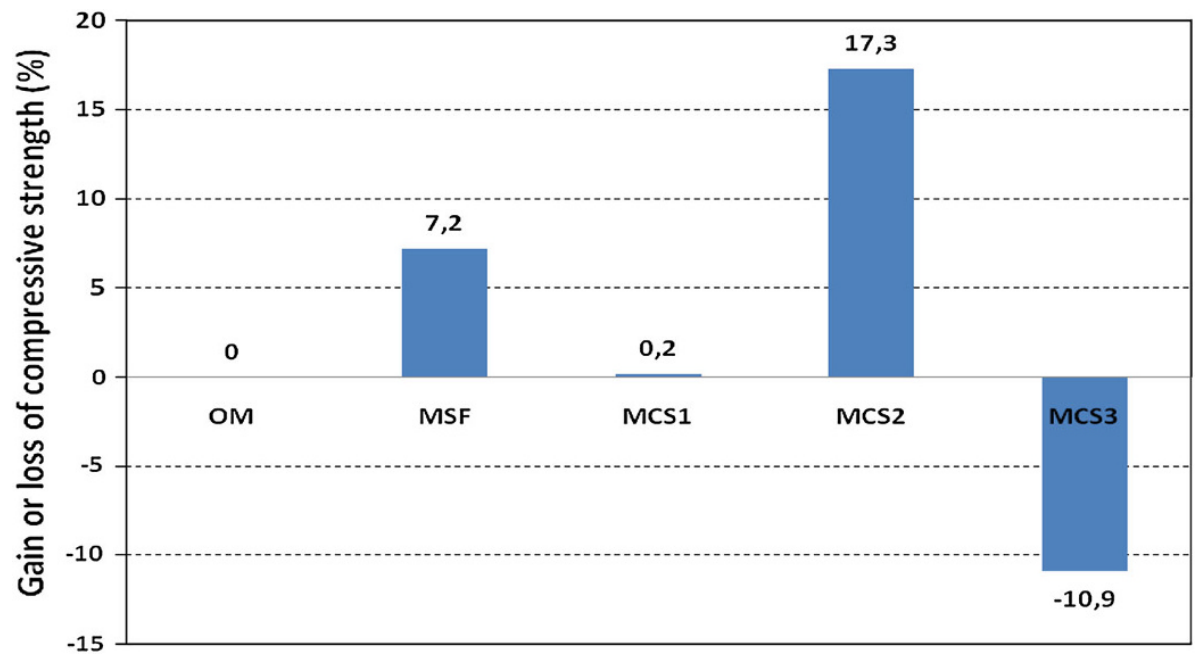

Fig. 12 Gain or loss in compressive strength of mortars with additions compared to $\mathrm{OM}$ after immersion in $\mathrm{Na}_{2} \mathrm{SO}_{4}$ during 60 days.

Figure 11, shows the state of various mortars immersed in sulfuric solution $\mathrm{Na}_{2} \mathrm{SO}_{4}$ after 60 days.

In the purpose of a comparative analysis of the mechanical properties of various mortars in the sulfate attack, we determined the rate of change of compressive strength at the age of 60 days. The rate of change in resistance $(\tau)$ is given in $\%$ by the following formula:

$$
\tau=\left(R_{c s}-R_{c w}\right) / R_{c w}(\%),
$$

where $R_{c w}$ is the compressive strength of mortar conserved in water; $R_{C S}$ is the compressive strength of mortar conserved in sulfatic medium.

The results obtained showed a gain of strength for all mortars except the mortar with $15 \%$ of calcined silt (Fig. 12). We observe an increase of the strength that appears to be due to the reaction of $\mathrm{Na}_{2} \mathrm{SO}_{4}$ with $\mathrm{Ca}(\mathrm{OH})_{2}$ to form gypsum according to the following reaction (Fig. 13):

$$
\mathrm{Ca}(\mathrm{OH})_{2}+\mathrm{Na}_{2} \mathrm{SO}_{4}+2 \mathrm{H}_{2} \mathrm{O} \rightarrow \mathrm{CaSO}_{4} \cdot 2 \mathrm{H}_{2} \mathrm{O}+2 \mathrm{NaOH} .
$$

$\mathrm{NaOH}$ : has a high alkalinity which promotes stabilization of $\mathrm{CSH}$, while the gypsum is formed only in the internal spaces of the hydrated cement paste (little or no expansion) which helps to increase the compactness of concrete and mechanical resistance in the Middle Ages therefore the compressive and flexural strength have increased at the age of 28 and 60 days. We should increase the age of specimens' immersion in the sulfate to see the effect of this latter.

The second reaction is between the gypsum formed and calcium aluminate of cement $\left(\mathrm{C}_{3} \mathrm{~A}\right)$, forming ettringite: $\mathrm{C}_{3} \mathrm{~A}$ $\mathrm{CaSO}_{4} \cdot 32 \mathrm{H}_{2} \mathrm{O}$ by the following reaction: 
$\mathrm{C}_{3} \mathrm{~A}+3 \mathrm{CaSO}_{4} \cdot 2 \mathrm{H}_{2} \mathrm{O}+26 \mathrm{H}_{2} \mathrm{O} \rightarrow \mathrm{C}_{3} \mathrm{~A} \cdot 3 \mathrm{CaSO}_{4} \cdot 32 \mathrm{H}_{2} \mathrm{O}$.

The ettringite is an expansive element which creates a physical and mechanical damage (changes in transport properties and porosity, cracks, loss of strength and cohesion). This leads to the ruin of the cementitious material, more or less long-term function of the attack (nature, content and concentration of sulfates in contact).

\subsubsection{Chloride Ions Penetration Effect}

The resistance to chloride ions penetration in the mortar and the concrete is one of the most important questions concerning the durability of the concrete structures. When the chloride concentration exceeds a certain threshold, a depassivation of steel occurs and there is a beginning of corrosion for reinforced steel (Thomas 1996; Alonso et al. 2000). Consequently, the development of protection materials with a resistance to chloride ions penetration is required for the concrete structures. For the tests we used cubic specimens $(10 \times 10 \times 10) \mathrm{cm}^{3}$. The mortars were made in accordance with the standard NFP 15-403 NF P (1996). Then the specimens are introduced into a concentrated $\mathrm{NaCl}$

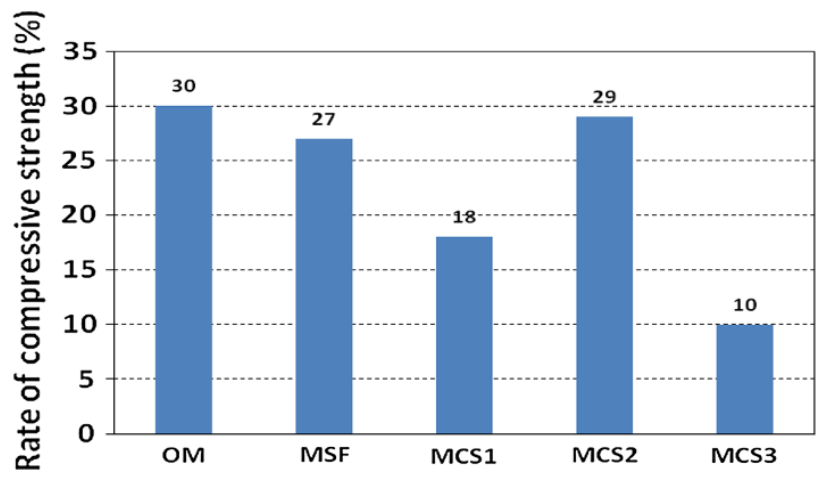

Fig. 13 Rate of compressive strength variation of mortars kept in $\mathrm{Na}_{2} \mathrm{SO}_{4}$ during 60 days compared to those kept in water. solution with $5 \%$. To evaluate the durability of the mortars from the chloride ions penetration, we followed the penetration depth evolution of the ions chlorides to 28 and 60 days. The solutions were changed every 7 days until the age of 28 days and every 28 days until the age of 60 days. Each test specimen is divided into two parts and then solution of silver nitrate $\mathrm{AgNO}_{3}$ was poured on each section according to the standard UNI 79287 (UNI 79287 1978). A whitish color appeared on the specimen surface, using a caliper measuring the chloride-ions penetration depth; the results are shown in Fig. 14. The test method followed in the present investigation to determine the chloride-ions penetration depth is reliable and accurate, and has also been recommended by other researchers (Erhan and Kasim 2007; Wee et al. 2000; Otsuki et al. 1992; Wee et al. 1999; Meck and Sirivivatnanon 2003).

The chloride-ions penetration depth of mortars, increase with the immersion period. Also note that the chloride-ions penetration depth of the mortar with additions is significantly lower than the ordinary mortar, and it reduces especially with $10 \%$ of calcined silt and silica fume. This is can certainly be related to the high pozzolanic reactivity of calcined silt and silicafume, can promote pozzolanic reaction of particles of this addition with the calcium hydroxide $\mathrm{Ca}(\mathrm{OH})_{2}$ released from cement hydration leading to pore size and grain size refinement processes which can strengthen the microstructure and reduce microcracking. This is explained also by the great finesse of these additions, these additions fill the pores and capillaries, increasing the compactness of the mortar which hinders the penetration of chloride ions.

\section{Conclusion}

The use of metakaolin in cement has gained significant importance because of the requirements of environmental protection and sustainable construction in the future.

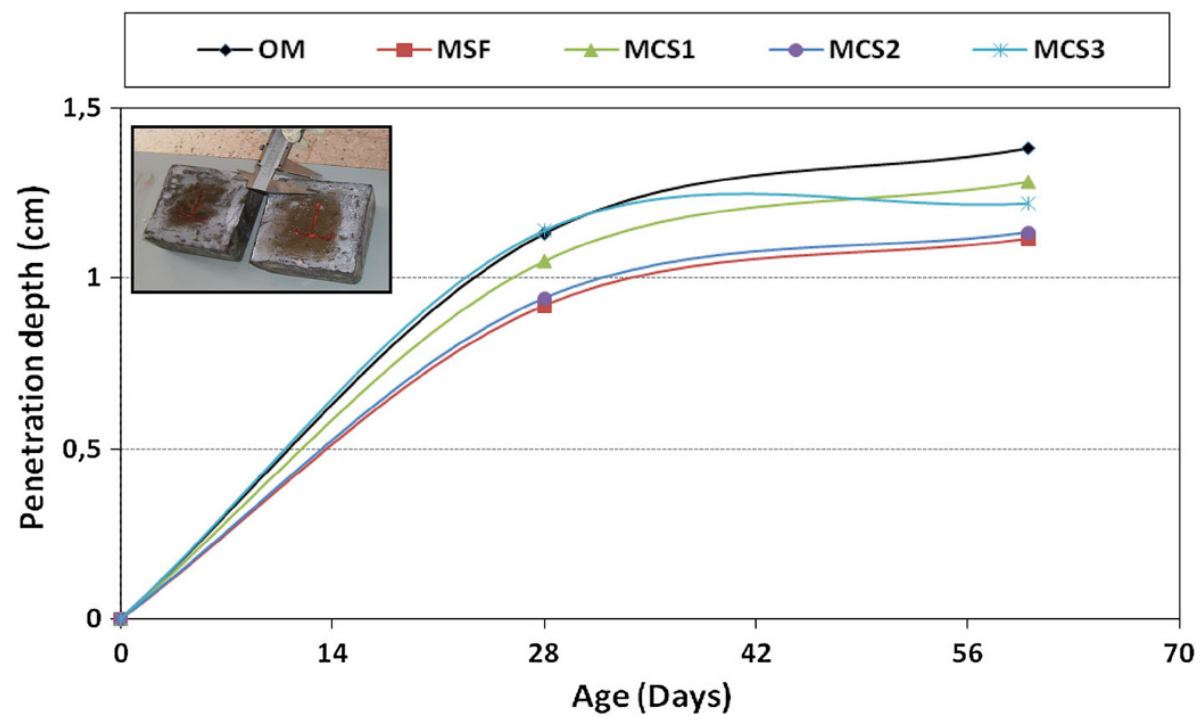

Fig. 14 Chloride-ions penetration depth. 
Depending on the results of the tests carried out on different mortars mixes, and based on the analysis, discussions, and comparisons with corresponding theoretical predictions, the following conclusions can be drawn:

- Metakaolin obtained from calcined silt (CS), has a pozzolanic reactivity relatively high $(75 \%)$ which has the value closest to that of silica fume.

- The study of mechanical performance showed retention of mechanical strength of mortars based on calcined silt and under certain conditions an improvement. The largest gain was obtained for a substitution rate of $10 \%$ of cement with calcined silt; an improvement of about $18 \%$ of the compressive strength at 28 days compared to the ordinary mortar is obtained.

- The substitution of cement by calcined silt has a beneficial effect on the durability, because this addition contributes to the densification of the hardened cement paste, by consumption of portlandite and forming $\mathrm{CSH}$ and $\mathrm{CAH}$, also the presence of high lime content in calcined silt $(17 \%)$ have contributed to conserve the basic PH of mortars which improve their durability, consequently the weight loss is limited.

- An increase of the strength of all mortars exposed to sulfatic attack appears, due to the reaction of $\mathrm{Na} 2 \mathrm{SO} 4$ with $\mathrm{Ca}(\mathrm{OH})_{2}$ to form gypsum, that complete the micro pores leading to a denser structure, which increases the compactness and this positively affects the mechanical strength at 28 and 60 days. It should increase the age of specimens' immersion in the sulfate to see the effect of this latter.

- The addition of calcined silt reduces the penetration of chloride ions in mortars.

- The composition which substituted $15 \%$ of cement is not appeared the good performance; compressive, flexural strength and durability but it has a similar performance, what is beneficial economic viewpoint, since it was replaced a large quantity of cement having a high manufacturing cost.

Finally, we can say that this experimental work opens the way for the use of silt of dam as metakaolin in the cement industry and to improve the physico-mechanical properties and the durability of cementitious materials.

\section{Open Access}

This article is distributed under the terms of the Creative Commons Attribution License which permits any use, distribution, and reproduction in any medium, provided the original author(s) and the source are credited.

\section{References}

Al Rawas, A. A., Hago, A. W., Al Lawati, D., \& Al Battashi, A. (2001). The Omani artificial pozzolans (Sarooj). Cement Concrete \& Aggregates, 23(1), 19-26.
Alonso, C., Andrade, C., Castellote, M., \& Castro, P. (2000). Chloride threshold values to depassivate reinforcing bars embedded in a standardized OPC mortar. Cement and Concrete Research, 30(7), 1047-1055.

Ambroise, J., Murat, M., \& Pera, J. (1986). Investigations on synthetic binders obtained by middle-temperature thermal dissication of clay minerals. Silicates Industries, 7(8), 99-107.

Ambroise, J., Martingale, S., \& Pera, J. (1992). Pozzolanic behavior of thermally activated kaolin. In 4th International conference of fly ash, silica fume, slag and natural pozzolans in concrete, Istanbul, Turkey (pp. 731-748).

Aquino, W., Lange, D. A., \& Olek, J. (2001). The influence of metakaolin and silica fume on the chemistry of alkali-silica reaction products. Cement and Concrete Composites, 23(6), 485-493.

ASTM C 267-96. (October 2001). Standard test methods for chemical resistance of mortars, grouts, and monolithic surfacings and polymer concretes. Annual book of ASTM standards. West Conshohocken, PA: ASTM International.

ASTM C 618. (January 2000). Standard specification for coal fly ash and raw or calcined natural pozzolan for use as a mineral admixture in concrete. Annual book of ASTM standards. West Conshohocken, PA: ASTM International.

Bager, G. S., Hansen, E. R., Wood, M. R., Neary, T., Beech, D. J., \& Jaquier, D. (2001). Production and use of calcined natural pozzolans in concrete. Cement, Concrete \& Aggregates, 23(2), 73-80.

Baronio, G., \& Binda, L. (1997). Study of the pozzolanicity of some bricks and clays. Construction and Building Materials, 11(1), 70-78.

Bénoît, O. (1969) Détermination de l'activité pouzzolanique d'une pouzzolane par voie Chimique. Bull liaison labo. P. et Ch., 126, D1-D5.

Butler, W. B. (1982). A critical look at ASTMC and C311, cement, concrete and aggregates. CCAGDP, 14(2), 68-72.

Chinje, M., \& Billong, N. (2004). Activité pouzzolanique des déchets de briques et tuiles cuites. African Journal of Science and Technology (AJST), Science and Engineering Series, 5(1), 92-100.

Erhan, G., \& Kasim, M. (2007). Comparative study on strength, sorptivity, and chloride ingress characteristics of air-cured and water-cured concretes modified with metakaolin. Materials and Structures, 40, 1161-1171.

Frias, M., de Rojas, M. I. S., \& Carbrera, J. (2000). The effect that the pozzolanic reaction of metakaolin has on the heat of evolution in metakaolin cement mortars. Cement and Concrete Research, 30, 209-216.

Ghrici, M., et al. (2007). Mechanical properties and durability of mortar and concrete containing natural pozzolana and limestone blended cements. Cement \& Concrete Composites, 29, 542-549.

Guneyisi, E., Gesoglu, M., \& Mermerdas, K. (2008). Improving strength, drying shrinkage, and pore structure of concrete using metakaolin. Materials and Structures, 41, 937-949.

Janotka, I. (1999). The influence of zeolitic cement and sand on resistance of mortar subjected to hydrochloric acid solution attack. Ceramics-Silikaty, 43(2), 61-66. 
Kostuch, J.,Walters, A., \& Jones, G. V. (1993). High performance concrete incorporating metakaolin-a review. In Concrete 2000. University of Dundee, Dundee, UK (pp. 1799-1811).

Kouloumbi, N., Batis, G., \& Pantasopoulou, P. (1995). Efficiency of natural Greek pozzolan in chloride-induced corrosion of steel reinforcement. Cement Concrete \& Aggregates, 17(1), 18-25.

Massazza, F. (1993). Pozzolanic cements. Cement and Concrete Composites, 15(4), 185-214.

Meck, E., \& Sirivivatnanon, V. (2003). Field indicator of chloride penetration depth. Cement and Concrete Research, 33, 1113-1117.

Mehta, P. K. (1981). Studies on blended Portland cements containing Santorin earth. Cement and Concrete Research, 11(4), 507-518.

Michel, V. (1989). La pratique des ciments, mortiers et bétons'. Edition le moniteur.

NF P 15-403. (1996). Sable normal et mortier normal. AFNOR, Paris.

NF P 15-411. (1996). Malaxeur. AFNOR, Paris, France.

NFP 15-400. (1996). Résistance à la flexion. Paris, France: AFNOR.

NFP 15-401. (1996). Résistance à la compression. Paris, France: AFNOR.

Nkinamubanzi, P. C., \& Aitcin, P. C. (2000). L'utilisation du laitier dans la fabrication du ciment et du béton. Ciments, Bétons, Plâtres et Chaux, 843(2), 116-125.

Otsuki, N., Nagataki, S., \& Nakashita, K. (1992). Evaluation of $\mathrm{AgNO}_{3}$ nitrate solution spray method for measurement of chloride penetration into the hardened cementitious matrix materials. ACI Materials Journal, 89(6), 587-592.

Poon, C. S., Lam, L., Kou, S. C., Wong, Y. L., \& Wong, R. (2001). Rate of pozzolanic reaction of metakaolin in high performance cement pastes. Cement and Concrete Research, 31, 1301-1306.

Ramezanianpour, A. A. (1987). Engineering properties and morphology of pozzolanic cement-concrete. PhD Thesis, University of Leeds, Leeds, UK.

Rodriguez-Camacho, R. E. (1998). Using natural pozzolans to improve the sulfate resistance of cement mortars. In V. M. Malhotra (Ed.), International conference, Bangkok, Thailand ACI SP-178 (pp. 1021-1039).

Rossignolo, J. A., \& Agnesini, M. V. C. (2004). Durabilty of polymer-modified lightweight aggregate concrete. Cement and Concrete Composites, 26, 375-380.

Sabir, B. B., Wild, S., \& Khatib, J. M. (1996). On the workability and strength development of metakaolin concrete. In Proceeding of the international conference concrete in the service of mankind, environmental enhancement and protection, Dundee, UK (pp. 651-662).

Sabir, B. B., Wild, S., \& Bai, J. (2001). Metakaolin and calcined clays as pozzolans for concrete: A review. Cement and Concrete Composites, 23, 441-454.
Safi, B., Benmounah, A., \& Saidi, M. (2011). Rheology and zeta potential of cement pastes containing calcined silt and ground granulated blast-furnace slag. Matériaux de Construction, 61(303), 353-370.

Safi, B., Yurtdas, I., \& Li, A. (2012). Use of silt of dams as a supplementary cementitious material in self-compacting mortars: Effect on physical and mechanical properties. In 12th International multidisciplinary scientific geoconference \& EXPO SGEM, Albena.

Said-Mansour, M., et al. (2005). Effets de la combinaison de la pouzzolane et du calcaire sur les propriétés des mortiers et des bétons. In Congrès international Réhabilitation des Constructions et Développement Durable, Alger 3 et 4 Mai 2005.

Samet, B., Mnif, T., \& Chaabouni, M. (2007). Use of a kaolinitic clay as a pozzolanic material for cements: formulation of blended cement. Cement and Concrete Composites, 29(10), 741-749.

Sayanam, R. A., Kalsotra, A. K., Mehta, S. K., Sing, R. S., \& Mandal, G. (1989). Studies on thermal transformations and pozzolanic activities of clay from Jammu region (India). Journal of Thermal Analysis, 35, 9-106.

Shvarzman, A., Kovler, K., Schamban, I., Grader, G., \& Shter, G. (2002). Influence of chemical and phase composition of mineral admixtures on their pozzolanic activity. Advances in Cement Research, 14(1), 35-41.

Tagnit-Hamou, A., Pertove, N., \& Luke, K. (2003). Properties of concrete containing diatomaceous earth. ACI Materials Journal, 100(1), 73-78.

Thomas, M. (1996). Chloride thresholds in marine concrete. Cement and Concrete Research, 26(4), 513-519.

UNI 79287. (December 1978). Concrete-determination of the ion chloride penetration. UNI-Ente Nazionale Italiano Di Unificazione, Milano, Italy piazza A. Diaz, 2.

Wee, T. H., Suryavanshi, A. K., \& Tin, S. S. (1999). Influence of aggregate fraction in the mix on the reliability of the rapid chloride permeability test. Cement and Concrete Composites, 21, 59-72.

Wee, T. H., Suryavanshi, A. K., \& Tin, S. S. (2000). Evaluation of rapid chloride permeability test (RCPT) results for concrete containing mineral admixtures. ACI Materials Journal, 97(2), 221-232.

Wild, S., \& Khatib, J. M. (1997). Portlandite consumption in metakaolin cement pastes and mortars. Cement and Concrete Research, 27(1), 137-146.

Zhang, M. H., \& Malhotra, V. M. (1995). Characteristics of a thermally activated alumino-silicate pozzolanic material and its use in concrete. Cement and Concrete Research, 25(8), 1713-1725.

Zivika, V., \& Bajz, A. (2002). Acidic attack of cement-based materials - a review. Part 2. Factors of rate of acidic attack and protective measures. Construction and Building Materials, 16(4), 215-222. 